\title{
Implementation of Data Warehouse in Human Resource Information System Using SEM-GeSCA
}

\author{
Muhammad Anshari ${ }^{[1]}$, I Putu Suryadharma ${ }^{[2]}$, and Wayan Rinas ${ }^{[3]}$ \\ [1][2] Department of Electrical and Computer Engineering, Post Graduate Program, Udayana University, \\ [3] Department of Electrical and Computer Engineering, Udayana University \\ Email: muhammad.anshari16@gmail.com
}

\begin{abstract}
Today, the changing nature of work and organization that occurs is quite high, causing the organization to be under pressure to adapt to changing circumstances. Work becomes more dynamic, making proactive behavior seen as a critical determinant of an organization's success. The purpose of this study was to identify the effect of $H R$ practices on proactive behavior, as well as the role of mediation of work attachment to the relationship. Hypothesis testing using Generalized Structured Component Analysis model. From the test results found that the attachment of work plays a role in mediating the influence of work attachment to partial mediation behavior (Partial mediation). Limitations This study is using cross sectional data, a specific type of company and does not use data discriminately. This study uses dimensional integration to test proactive behavior that is directly influenced by HR practices and indirectly mediated by work attachment.
\end{abstract}

Keywords: HR Practice, Work Attitude, Proactive Behavior, Generalized Structured Component Analysis

\section{PRELIMINARY}

The current labor market, characterized by flexibility, rapid innovation and continuous change, so organizations look for specific competencies and behaviors of employees who are able to adapt to the needs of the workforce[1]. Changes in the nature of work and organization that occur, causing the organization is under pressure to adapt to changing[2]. The company expects employees to exceed employment limits [3]. Work becomes more dynamic, making proactive behavior seen as a more critical determinant of the success of an organization[4]. Proactive is very important in today's decentralized workplace, where competition is greater and increasing pressure to innovate [5]. Proactive behavior in work is an important factor in changing the work environment [2]. Proactive behavior represents selfinitiative which is an anticipatory action to change and improve a particular situation or self [3]. Bateman and Crant [4] describe proactive behavior not only as an individual construct, but also an interactional relationship where people can and intentionally change the environment.

Maden [3] states the practice of Human Resources (HR) with its components of high involvement HR practices affect proactive behavior, by stimulating employee engagement and goal-oriented learning. While Tummers [2] found that HR practices affect proactive behavior. The practice of high-involvement human resources is a variety of HR practice measures incorporated into a model first introduced by Lawler in 1986. This practice has a goal to develop employee commitment and involvement in the workplace [6]. Meanwhile, work engagement is a positive thing, a job that includes all thoughts characterized by passion, dedication, and absorption[1], in which one's engagement, satisfaction, and enthusiasm for the work done[7].

This research takes consultancy services company with non-construction specifications incorporated in the Indonesian National Association of Consultants Bali (Inkindo Bali). A consultant is a service profession that seeks and finds solutions and solutions, based on the excellence of its professional expertise and professional competence, complete and reliable, to the needy, with honest, integrity, impartial, impartial On the principles of ethical codes and professional conduct. Non construction service is a service or service with non-physical job qualification (study). Customization and high pressure from stakeholders, make the consultant consultants should be smart in finding a way for every circumstance that occurred. This makes a consultant must have highmotivated employees to take initiative and have high innovation[3]-[5]. This study is a development of Maden [3] and Tummers [2] by examining the direct effect of HR practices on proactive behavior and the role of mediation of work attachment to those influences. This study uses high-involvement $\mathrm{HR}$ practices as dimensions that measure HR Practices and dimensional integration from Bateman and Crant [4] with Parker and Collins [5] to measure proactive behavior.

\section{A. Proactive behavior}

Proactive behavior is a particular form of motivational behavior[8]. Proactive action is an action that is motivated, conscious, and has a well-directed goal that is recognized in the expectancy theory. Individuals want and need to be proactive or see the value associated with being proactive to reach a different future [5]. This is in line with Bateman and Crant [4] who explained that individuals are proactive, actively creating environmental change. Parker [5] asserts that proactive behavior has three key attributes: self-starting, change-oriented, and focused on the future[5], [7], [9]. 
Proactive behavior is challenging the status quo, taking initiative against a situation as it happens and what will happen[4]. Proactive is the way to improve decision making and performance[5]. Being proactive is about taking control to make things happen rather than watching things happen, anticipate and prevent problems, and seize opportunities. It involves self-effort, taking the initiative to bring about change in the work environment and/or self to reach a different future[3]-[5]. This is in contrast to Grant states that proactive behavior is second nature, where behavior is created through culture, family life, educational experience or the cumulative impact of a workplace that does not accept proactive employees. Employees need to be proactive when developing careers.

Researchers have proven that employees who have proactive characters tend to have a proactive role in the workplace, such as being active and providing feedback, and trying to have control over the social environment and oneself has a personal initiative, problem prevention, individual innovation, taking charge, and voice.

B. The practice of human resources

The practice of human resources is a motivation that influences employee behavior in companies such as commitment, proactive, trust and vitality related to change management [3]. HR practices are closely related and affect employee performance in a company. Some of the things companies do in collecting and using the intelligence, ideas and motivations of all workers, where companies choose from a variety of HR practices, by Didier \& Guerrero [6] are described as a high-involvement human resources practice first introduced by Lawler in 1986, with a view to developing employee commitment and involvement in the workplace. In this study, Maden's dimension is based on the conceptual framework proposed by Lawler, which is a high-involvement human resources practice which is divided into five sections, Empowerment, Competence Development, Information Sharing, Recognition (recognition) Fair Rewards (fair reward).

\section{Work attachments}

Work attachments are assumed to be opposite to burnout, bound employees are energetic and effectively connected to work activities, and employees see themselves as capable of handling well the demands of the job. Employee Engagement as a new concept in which one's involvement, satisfaction, and enthusiasm for the work is done, something that is emotionally embedded in the work of the employee himself. Work attachment is an active behavior about high involvement

In employment. Shantz [10] states that employees holding jobs with high levels of autonomy, diverse tasks, significant tasks and feedback will have higher attachments, reciprocity, higher performance ratings than supervisors, and little or none Do deviant behavior. The attachment significantly affects innovative work behavior[11]. With regard to work attachment, an organization can potentially develop a strong innovative culture, improving the relationship between employees and leaders which can improve a company's performance. The bound employee does not work hard because the inner drive is strong and unbearable, but because of the feeling that work is fun. Work attachment is characterized by vigor (spirit), dedication (dedication), and absorption (absorption)[1]. This study examines the role of mediation of work attachment in the influence of HR practices on proactive behavior. To know the role before it is necessary to know the direct effect of HR practices on work attachment and the influence of work attachment to proactive behavior.

HR practices affect proactive behavior[2]. Moments team members feel appreciated, acknowledged and supported by leaders, team members will be more willing to share responsibility, work together and commit to team collective goals, which can then lead to higher team proactive behavior. When employees feel that their contribution is not heard, the motivation of the rich will decrease (demotivate) and productivity will be disrupted. Results indicate the importance of empowerment variables and individual differences to stimulate proactive behavior within an organization. Marescaux states that HR practices have a significant effect on employee behavior in the workplace.

\section{RESEARCH METHODOLOGY}

\section{A. Participants and Procedures}

The sample of this research is 98 technical and administrative employees working in consultancy services company with non-construction specification in Denpasar city incorporated in Indonesian Consultant Association of Bali. The survey was conducted by distributing 105 questionnaires directly to 10 companies. All the questionnaires returned, but there were 7 questionnaires that were not complete so they were not used in the study. The research instrument is translated into Indonesian before it is distributed.

Characteristics of the sample based on the recapitulation of the questionnaire, the most gender was male by $64.29 \%$ with the most $18-24$ years age range of $40.82 \%$. For the education level most participants $\mathrm{S} 1$ by $70.41 \%$. While the working period has a range of 1 year to more than 20 years, most with a range of $1-5$ years of $66.33 \%$.

\section{B. Measurements}

Proactive Behavior. Proactive behavior is measured in Bateman and Crant for proactive personality dimensions, Parker and Collins for the dimensions of problem prevention, individual innovation, voice, taking responsibility. Proactive personality is measured by 16 indicators (e.g. "I have the power to make constructive change wherever I am"), preventing problems with 3 indicators (e.g. "I often try to develop effective procedures over the long term, even if there are obstacles to getting started) Individual innovations with 3 indicators (e.g. "I often generate creative ideas"), sounds with 4 indicators (e.g. "I often communicate views on work issues, with coworkers even if my views are different from them"), Responsibility takers with 3 indicators (e.g. "I often try to 
bring improved procedures at work"). The reliability of each dimension is $0.91,0.79,0.85,0.82$, and 0.90. Each item is measured by Likert scale 5 ( 1 = "never", 5 = "always").

Human Resource Practice. Items for measuring this variable are based on Pare and Tremblay (2007) that have 5 dimensions. Empowerment practices are measured by 3 indicators (e.g. "I am given flexibility to manage jobs"), developing competencies with 5 indicators (e.g. "I can develop skills to increase opportunities promoted"), sharing information with 8 indicators (e.g. "I regularly given information about the company's future projects"), recognition with 6 indicators (e.g. "The advice I give to the company is taken seriously"), fair rewards with 5 indicators (e.g. "I feel that my salary is fair Internally"). The reliability of each dimension is $0.81,0.84,0.91,0.81$ and 0.84 , respectively. Individual indicators measured by Likert scale 5 ( 1 = "strongly disagree", 5 = "strongly agree")

Work Attachment. Measurements on work attachment variables using the Utrecht Work Engagement Scale developed by Schaufeli et al. UWES consists of 3 dimensions: the spirit with 6 indicators (e.g. I feel a lot of energy while at work), dedication with 5 indicators (e.g. I feel that my job goals are clear), absorption with 6 indicators (e.g. I feel the time is so fast Passed when I worked). The reliability of this dimension is $0.72,0.92$, 0.88 . Individual indicators measured by Likert scale 5 ( $1=$ "never", 5 = "always")

\section{Analysis strategy}

Testing on the model is done in three stages. The first stage tests the second order data using the Generalized Structured Component Analysis (GSCA) with GSCA software to test the structural model. In GSCA analysis parameter estimation using least squares method. The assessment criteria used by FIT and AFIT (0-1) have big a greater value meaning, the higher the variation on the variables that can be explained by the model. GFI (close to 1) and SRMR (close to 0) indicate good fit. The second test is the Sobel Test to determine the indirect effect of HR practice variable and proactive behavior and the third stage refers to Hair et al., To analyze the role of mediation of work attachment.

\section{RESUlts AND DisCUSSION}

A. The ETL (Extraction, Transformation, Loading) process from the data source to the data warehouse database

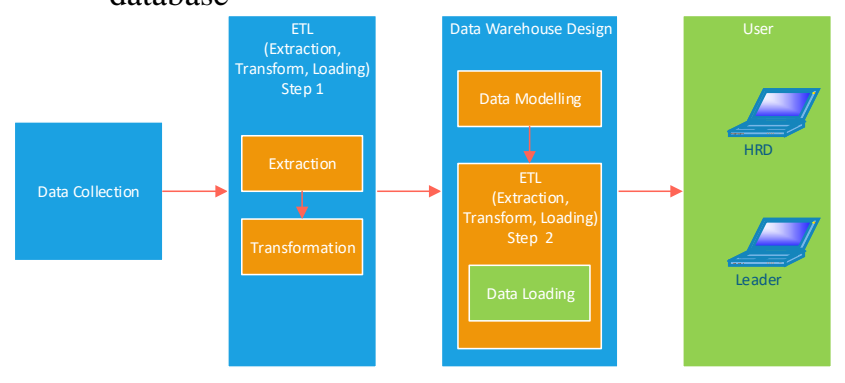

Figure 1 ETL Process

Table 1 Variable

\begin{tabular}{|c|c|}
\hline \multirow[t]{3}{*}{ Empowerment } & Discretion \\
\hline & Autonomy \\
\hline & Freedom \\
\hline \multirow{5}{*}{$\begin{array}{l}\text { Development } \\
\text { of competence }\end{array}$} & Develop skills \\
\hline & Job rotation \\
\hline & Professional development \\
\hline & Apply the skills \\
\hline & Encouraged to apply skills \\
\hline \multirow{8}{*}{$\begin{array}{l}\text { Sharing } \\
\text { information }\end{array}$} & Information about the project \\
\hline & Information about finance \\
\hline & Information about performance \\
\hline & Information on technological orientation \\
\hline & Information about the level of customer satisfaction \\
\hline & Suggestions about effectiveness are noticed \\
\hline & Information on performance evaluation criteria \\
\hline & Information about new products \\
\hline \multirow[t]{6}{*}{ Recognition } & Suggestions on the company are noticed \\
\hline & Suggestions are acted upon \\
\hline & Award from colleagues \\
\hline & Recognition of supervisor \\
\hline & Recognition in writing \\
\hline & Congratulations \\
\hline \multirow[t]{5}{*}{ Fair Rewards } & Salaries are fair internally \\
\hline & My salary is fair external \\
\hline & A fair mandate \\
\hline & Decent compensation \\
\hline & Salary is worth a performance reflection \\
\hline \multirow[t]{6}{*}{ Spirit } & Have a lot of energy \\
\hline & Powerful in working \\
\hline & Going to work is the first thought \\
\hline & Working for a very long time \\
\hline & Resilient mentally \\
\hline & Last \\
\hline \multirow[t]{5}{*}{ Dedication } & The purpose of the work is clear \\
\hline & Enthusiastic \\
\hline & Inspire yourself \\
\hline & Proud \\
\hline & Full of challenges \\
\hline \multirow[t]{6}{*}{ Absorption } & Time flies so fast \\
\hline & Forget the various things around \\
\hline & Work intensively \\
\hline & Often dissolves \\
\hline & Carried away by the situation \\
\hline & It's hard to get away \\
\hline \multirow{17}{*}{$\begin{array}{l}\text { Proactive } \\
\text { personality }\end{array}$} & Improve life \\
\hline & Encouraged to make changes \\
\hline & Encourage others \\
\hline & Have the power to make changes \\
\hline & Enjoyed when looking for a solution \\
\hline & Interested in seeing ideas come true \\
\hline & Fix something that you do not like \\
\hline & Make something happen that I have trusted \\
\hline & Glad to be the champion for the idea \\
\hline & Superior in identifying opportunities \\
\hline & Looking for a better way \\
\hline & Sure of an idea \\
\hline & Challenging the status quo \\
\hline & Not afraid to face problems \\
\hline & Turning a problem into an opportunity \\
\hline & See opportunities \\
\hline & Helping people in trouble \\
\hline \multirow{3}{*}{$\begin{array}{l}\text { Prevention of } \\
\text { problems }\end{array}$} & Develop effective procedures \\
\hline & Find the root of the problem \\
\hline & Plan how to prevent problems \\
\hline \multirow{3}{*}{$\begin{array}{l}\text { Individual } \\
\text { innovation }\end{array}$} & Produce creative ideas \\
\hline & Looking for ways \\
\hline & Promote ideas \\
\hline
\end{tabular}




\begin{tabular}{|l|l|}
\hline Communication & Communicating views \\
\cline { 2 - 2 } & Encourage co-workers \\
\cline { 2 - 2 } & Information about the issue requires an opinion \\
\cline { 2 - 2 } & Speaking of new ideas \\
\hline \multirow{2}{*}{$\begin{array}{l}\text { Take } \\
\text { responsibility }\end{array}$} & Bringing the repair procedure \\
\cline { 2 - 2 } & Apply new work methods \\
\cline { 2 - 2 } & Looking for a solution \\
\hline
\end{tabular}

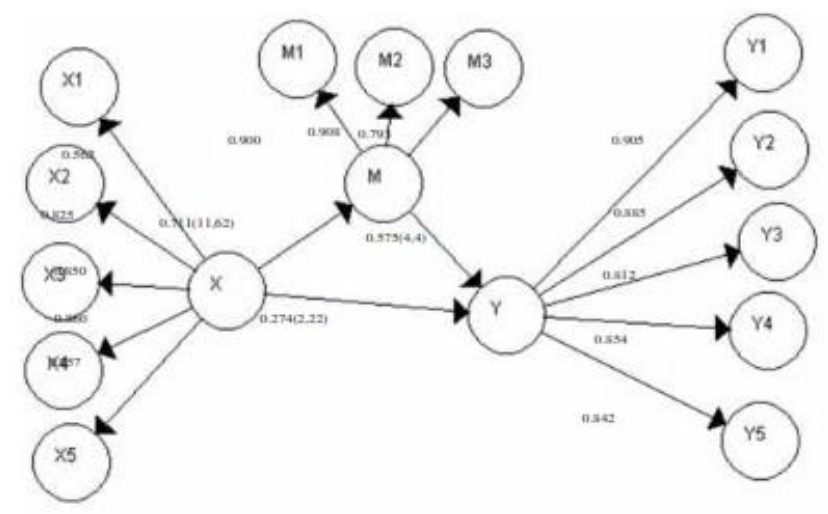

Figure 2 Path Coefficient between Variables and Dimensions

\section{B. Results}

1. Outer Model

Evaluation of outer model on GSCA model in this research is done three

Stage i.e. on the measurement model, structural model and overall model. As for each stage has a different meaning. The outer evaluation of the model is described in the next presentation.

a. Measure of fit measurement model

Convergent Validity. Convergent validity describes the size of the correlation between reflexive indicator scores and dimension scores. In the variable of HR practice, overall laoding estimate has positive value $>0.5$, and $\mathrm{CR}$ value at $\mathrm{SMC} \geq 2$. For each dimension, the indicator on empowerment dimension which has the highest loading factor value is X1.1 (0.884), dimension Competence development on indicator X2.5 (0.85), information sharing dimension on indicator X3.4 (0.859), recognition dimension on indicator X4.1 (0.79), X4.5 $(0.79), \mathrm{X} 4.6(0,79)$, as well as a fair reward dimension on the X5.5 indicators (0.864). The overall work attachment variable has a loading estimate> 0.5 with the critical ratio (CR) value at $\mathrm{SMC} \geq 2$. The indicators with the highest loading estimate values in each dimension are, the spirit dimension in M1.1 indicator (0.838), dimension Dedication to the M2.1 indicator (0.872), and the absorption dimension of the M3.5 indicators (0.812). Furthermore, the proactive behavior variable mostly has a factor loading value $>0.5$ and $\mathrm{CR}$ at $\mathrm{SMC} \geq 2$. There is one indicator that does not match the criteria i.e. Y1.1 indicator $(0.459, \mathrm{CR}=1.96)$ is invalid on sig. 0.05 . Indicators that have the highest score in each dimension include the proactive personality dimension on the Y1.12 indicators (0.725), the dimension of prevention of the problem on the indicator Y2.2 (0.869), the individual innovation dimension on the Y3.1 indicator (0.887), the dimension of the voice on the Y4 indicator .3 (0.871), and dimensions take responsibility on the Y5.2 indicators (0.916). The majority of indicators have a loading estimate value> 0.5 and significant, then $\mathrm{CR}$ at $\mathrm{SMC}$ has a value of $\geq 2.00$. It shows that latent constructs have good convergent validity with normal bootstrap distributions.

Discriminant Validity. Discriminant validity is measured by comparing the value of $\sqrt{ } \mathrm{AVE}$ (Average Variance Extracted) of each latent variable to the value of correlation among other latent variables in the model. The value of the latent variable $\sqrt{ } E \mathrm{AV}>>$ the correlation value of the latent variable with all other latent variables is said to have good discriminant validity. All variables have an $\sqrt{ }$ AVE value $>$ correlation value of latent variables with other latent variables, indicating latent variables having good discriminant validity (table 1). The correlations of latent variables are each dimension larger in each variable compared to that value in other variables, so it can be stated that the dimensions are appropriate for measuring each variable (table 2).

Internal Concerns Reliability. Internal consistence reliability indicates that the indicator group measuring a variable has good consistent internal reliability if it has an alpha value (Cronbach's Alpha) $\geq 0.6$. The test results show that all variables have alpha value $>0.6$, so it can be stated that all variables have good consistent internal reliability (Table 1).

Table 2 Value AVE, $\sqrt{ }$ AVE and Alpha's Cronbach Latent Variables

\begin{tabular}{|c|l|c|c|c|}
\hline Num. & Dimensions & AVE & VAVE & Alpha \\
\hline 1 & Empowerment & 0.721 & 0.849 & 0.803 \\
\hline 2 & Competence development & 0.642 & 0.801 & 0.860 \\
\hline 3 & sharing information & 0.622 & 0.789 & 0.912 \\
\hline 4 & Recognition & 0.574 & 0.758 & 0.850 \\
\hline 5 & Fair rewards & 0.672 & 0.820 & 0.877 \\
\hline 6 & Spirit & 0.481 & 0.694 & 0.774 \\
\hline 7 & Dedication & 0.689 & 0.830 & 0.885 \\
\hline 8 & Absorption & 0.574 & 0.758 & 0.848 \\
\hline 9 & Proactive personality & 0.423 & 0.650 & 0.901 \\
\hline 10 & solution to problem & 0.719 & 0.848 & 0.803 \\
\hline 11 & Individual innovation & 0.792 & 0.890 & 0.869 \\
\hline 12 & Sound & 0.680 & 0.825 & 0.844 \\
\hline 13 & Take responsibility & 0.800 & 0.894 & 0.875 \\
\hline
\end{tabular}

Table 3 Correlation of Latent Variables by comparison $\sqrt{ }$ AVE

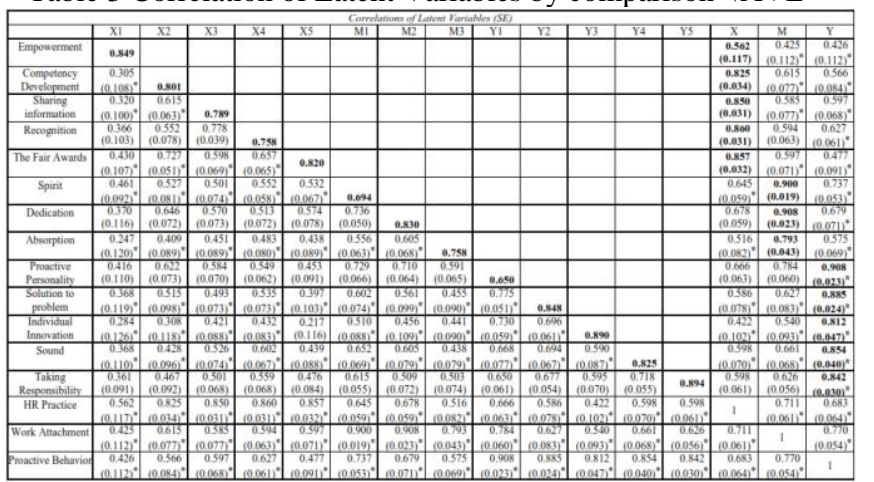

* significant at .05 level 
b. Measure of fit on Structural Model

In the measurement model, the goodness of fit model is measured by looking at the FIT value of the test output. FIT values ranging from 0 to 1 show the total variant of all variables that can be explained by the structural model. The value of FIT in this study has a value of 0.605 which means that the diversity can be explained by the structural model of $60.5 \%$, and $39.5 \%$ can be explained by other variables. In this research, the AFIT value of 0,595 or variability of variables can be explained by the model of $59.5 \%$ and $40.5 \%$ can be explained by other variables. Based on the value of FIT and AFIT model is formed is good and appropriate. More clearly can be seen in table 3 .

\section{c. Measure of fit Overall Model}

Goodness of fit in the overall model is known by looking at the value of GFI (unweighted least-squares) and SRMR (standardized root mean square residual) at the output. The model is said to be good if the value of GFI close to 1 and SRMR value close to 0 . In this study when viewed in table 3 GFI value of 0.989 and SRMR of 0.105 , then it can be said the model shows a good fit.

\section{Inner Model}

Inner model evaluation in this research is done on structural model using formula R2 and Q2 predictive relevance. The evaluation of structural model aims to find out how big the exogenous variable of HR Practice - High involvement $(\mathrm{X})$ can explain or influence variants on variables endogenous attachment of work (M) and proactive behavior (Y). Analysis of R2 using GeSCA software $(X=0,000, M=0,506, Y=0,630)$. Based on the calculation, obtained value of $\mathrm{Q} 2=0.817$ or $81.7 \%$ which means that predictive relevance is strong. A score of $81.7 \%$ states that variations in proactive behavior variables can be explained by HR practice variables and work attachments of $81.7 \%$. While $19.3 \%$ is explained by other variables outside the research model.

\section{Discussion}

Tests conducted in this study include testing the effect of HR practices on proactive behavior, the influence of HR practices on work attachment, the influence of work attachment to proactive behavior, and the influence of HR practices on proactive behavior mediated by work attachment. Data processing has been done using GeSCA 2013 program, get the results as described in table 4. Testing of HR practice variables with proactive behavior has an estimate value of 0.274 with $C R$ value of 2.22. (CR $\geq 2.00$, sig .05) then hypothesis H1 accepted, HR Practice have positive and significant influence to proactive behavior. The test between HR practice variable with work attachment shown in table 4 has estimate value of 0.711 and $C R$ value of 11,53 . CR value of $11.53 \geq 2.00$ on sig. 0.05 , indicating a positive and significant value. It states that $\mathrm{H} 2$ is accepted. Relationship of work attachment with proactive behavior, test result showed positive and significant value that is value of loading estimate 0,576 with $\mathrm{CR}$ value 4,83 . CR value $4,83 \geq 2.00$ on sig. 0.05 indicates that the third hypothesis $(\mathrm{H} 3)$ is accepted.

Tests of indirect influence between HR practice variables and proactive behavior using the sobel test. The results of the test sobel states that $z_{-}$value has a value of 7.21. The value is $\geq 1.96$. Thus it can be stated that HR practice variables have an indirect effect on proactive behavior through job attachment variables. Testing the role of mediation of work attachment variables refers to Hair et al. First, examine the direct effects of HR practice variables on proactive behavioral variables by involving job attachment variables $(\mathrm{CR}=2.22, \mathrm{CR} \geq 2.00$, sig. 0.5). Second, examine the effect of HR practice variables on proactive behavioral variables on models without involving work attachment variables (0.694 and CR 9,96, $\mathrm{CR} \geq 2.00$, sig.0.5). Third, examining the effect of the variable of work attachment to the proactive behavior variable $(\mathrm{CR}=4,4, \mathrm{CR} \geq 2.00$, sig. 0.5$)$. From the test results it can be concluded that work attachment plays a role in mediating the influence of HR practices on proactive behavior (H4 accepted), and the role of mediation is partial (mediation).

Table 4 Path Coefficients among Variable Research

\begin{tabular}{lccc}
\hline & Estimate & $\boldsymbol{S E}$ & $\boldsymbol{C R}$ \\
\hline HR Practice $->$ Work Attitude & 0.711 & 0.061 & $\mathbf{1 1 . 6 2} *$ \\
\hline HR Practice -> Proactive Behavior & 0.274 & 0.123 & $\mathbf{2 . 2 2}^{*}$ \\
\hline Work Attitudes -> Proactive Behavior & 0.575 & 0.131 & $\mathbf{4 . 4}^{*}$ \\
\hline $\begin{array}{l}\text { Practive SDM -> Proactive Behavior } \\
\text { (no mediation variables in the model }\end{array}$ & & & \\
\hline CR* $=$ significant at .05 level & & &
\end{tabular}

Proactive behavior refers to the belief that a person can do something and has reason to do so. The presence of a personal character towards proactive behavior as a general construct that examines behavior intended to make changes (Bateman \& Crant, 1993; Grant \& Ashford, 2008; Parker et al., 2010). The results of data processing show that HR practices have a positive and significant impact on proactive behavior. If the application of $\mathrm{HR}$ practices increases, employees will show improvement in proactive behavior. Empowerment practices, competent development practices and fair reward practices are wellregarded in their application. While the practice of sharing information and recognition practices is still considered low by employees. It certainly affects the proactive behavior of employees in the company. This study supports previous research which states that HR practices have a positive and significant influence on proactive behavior of Tummers. The results are also in line with Grant et al. stating that employee proactive behavior is related to the supervisor's assessment of the behavior as a contributor to the performance and attitudes shown.

Work attachment plays a role in mediating HR practices on proactive behavior. Maden [1] who states that when the practice of human resources is improved it will affect the attachment of work and it affects the increasing proactive behavior of employees. This study is consistent with previous research that states that companies that value resources and care for their well-being will encourage employees to be tied to work and demonstrate 
higher proactive behavior. Salanova and Schaufeli argue that work attachment fully mediates the impact of work resources on proactive behavior in the workplace, by increasing resources for increased job attachment, which indirectly increases in proactive work behavior. The role of work attachment in mediating the influence of HR practices on proactive behavior is partial mediation. This is because the influence of HR practices on work attachment has positive and significant value, then the influence of work attachment to positive and significant positive proactive behavior, and the direct influence of HR practices on proactive behavior has positive and significant values[12].

Finally, HR Practice has a positive and significant influence on proactive behavior. Consulting firms that possess and apply good and appropriate HR practices can directly improve the employee's proactive behavior in the company. HR practices have a positive and significant influence on job attachment variables. When companies treat employees as valuable resources, employees will become more attached to their work. Work attachment has a positive and significant influence on proactive behavior. Work with high attachments will have high initiatives to change their environment. The role of work attachment in mediating the influence of $\mathrm{HR}$ practices on proactive behavior is partial. A good HR practice will increase the work attachment which will make employees have high proactive behavior.

\section{CONCLUSIONS}

1. The result of the application of data warehouse in HR practices has a positive and significant influence on proactive behavior.

2. Consulting firms that possess and apply good and appropriate HR practices can directly improve the employee's proactive behavior in the company.

3. HR practices have a positive and significant influence on job attachment variables.

a. When companies treat employees as valuable resources, employees become more attached to their work. Work attachment has a positive and significant influence on proactive behavior.

b. Highly attached employees will have high initiatives to change their environment. The role of work attachment in mediating the influence of HR practices on proactive behavior is partial. A good HR practice will increase the work attachment which will make employees have high proactive behavior

\section{REFERENCES}

[1] M. Salanova and W. B. Schaufeli, A cross-national study of work engagement as a mediator between job resources and proactive behavior. The International Journal of Human Resource Management. 2008.

[2] L. Tummers, P. M. Kruyen, D. . Vijverberg, and T. J. Voesenek, "Connecting HRM and Change
Management: The Importance of Proactivity and Vitality," J. Organ. Change Manag., 2015.

[3] C. Maden, Linking High Involvement Human Resource Practices to Employee Proactivity. Personnel Review. 2015.

[4] J. M. Crant, "Proactive Behavior in Organizations," J. Manag., 2000.

[5] A. . Grant, S. Parkers, and C. Collins, Getting credit for proactive behavior: supervisor reactions depend on what you value and how you feel. 2009.

[6] V. B. Didier and S. Guerrero, Impact of social innovations on French companies' performance. Measuring Business Excellence. 2002.

[7] S. P. Robbins and T. . Judge, Organizational behavior (fifteen edition), 5th ed. USA: Prentice Hall, 2013.

[8] A. . Grant and S. J. Ashford, "The dynamics of proactivity at work," Res. Organ. Behav., 2008.

[9] G. Moorhead and R. . Griffin, Perilaku Organisasi: Manajemen Sumber Daya Manusia dan Organisasi. Jakarta: Salemba Empat, 2013.

[10] A. Shantz and K. Alfes, "The Role of Employee Engagement in The Relationship Between Job Design and Task Performance, Citizenship and Deviant Behaviours,” Int. J. Hum. Resour. Manag., 2013.

[11] U. . Agarwal and S. Datta, innovative work behaviour and turnover intentions. Career Development International. 2012.

[12] J. . Hair, R. . Anderson, R. . Tatham, and W. . Black, Multivariate Data Analysis (seventh ed.). New Jersey: Pearson Education, 2010. 